\title{
Influence of Teacher Performance Appraisal on Effectiveness in Curriculum Evaluation in Kenyan Public Secondary Schools
}

\author{
Joash Okello Aloo
}

Kabianga National School, Kabianga

\section{Dr. Jack Odongo Ajowi}

Department of Educational Administration and Management, Jaramogi Oginga Odinga University of Science and Technology

\section{Dr. Peter Jairo O. Aloka}

School of Education, Jaramogi Oginga Odinga University of Science and Technology

Doi: 10.1515/ajis-2017-0024

\begin{abstract}
The objective of the study was to establish the impact of Teachers Performance Appraisal(TPA) policy on effectiveness in curriculum evaluation in public secondary schools in Kenya. The study employed a Correlational research design. Additionally, the study used Stratified random sampling technique to select 179 Principals and 179 Deputy Principals. Consequently, the study used questionnaires to collect data from the Principals and Deputy Principals. The study also tested reliability of the instruments for data collection by assessing the scale's internal consistency using Crobanch's alpha, and reliability coefficient of at least 0.7 was achieved. Validity was determined by experts in Educational Administration of JaramogiOgingaOdinga University of Science and Technology. Quantitative data was analyzed by using descriptive and inferential statistics. The study established that TPA policy had a significant positive influence on curriculum evaluation by teachers $(r=.726, p<.05)$. The study confirmed that TPA: accounted for $52.5 \%$ of the variation in curriculum evaluation. The study established TPA to be a significant predictor of curriculum evaluation $[F(1,316)=351.92, p<.05)]$. The study recommends that the Kenyan Teachers Service Commission should enhance the use of reports when making decisions on teachers to be deployed to senior positions and those to be promoted to the next job groups. Such a step would make teachers respect and adhere to the policy guidelines. This is because the study reported that more teachers had embraced TPA with a view that it would be used to determine their suitability promotion.
\end{abstract}

Keywords: Teacher Performance Appraisal (TPA), Policy, Curriculum Evaluation, Schools, Kenya

\section{Introduction}

The Universal Declaration of Human Rights implemented by the United Nations General Assembly in December 1948 guaranteed individuals a variety of fundamental liberty with education serving as an elementary right essential for the achievement of all other freedoms (Ekwuene, 2009). To attain quality education, stakeholders should allow young people should have access opportunities for acquiring desired attitudes, skills, and values that will permit them to lead a productive and happy life's and discharge their social duties for the benefit of the society. The mandate to shape learners is vested on teachers, and therefore their role is crucial in achieving quality education as a fundamental right. Teachers at all heights of education are the bedrock and foundation of quality education in the society (Clarke, 2006). In line with this opinion, teachers should be able to monitor 
students' progress, provide guidance services, and manage both knowledge and students. Castler (2010) indicates that principals by virtue of their position are the managers. Additionally, the quality of managerial functions determine to a large extent their success or failure. Principals should, therefore, provide teachers with supportive management practices regardingutilization and workload of available material and professional resources. Management support methods in this context infer the provision of enabling an environment for teachers to offer the needed services effectively in the school system.

Performance appraisal system is an important constituent of the whole human resource management function in the civil service (The Republic of Kenya, 2008). The appraisal predicated upon the principle of setting agreed performance targets, work planning, reporting, and feedback. The general objective of the performance appraisal system is to improve and manage performance of the civil service. Improving and managing performance of civil service would enable anadvanced level of staff involvement and participation in delivery, evaluation, and planning of work performance. Republic of Kenya (2008) indicates that Performance Appraisal System (PAS) programme should consist of the following; Setting of performance targets, work planning, values, and monitoring, competency assessment, evaluation, and end of year appraisal. Likewise, TSC (2003) notes that a public officer shall improve the level of professionalism and standards of performance in his organization to the extent appropriate for his office. According to the Education Conference of 2005 in Kenya, low level of teacher commitment to curriculum implementation in schools results in poor performance in secondary education among others (The Republic of Kenya, 2008).

Teachers Service Commission (2015) gives direction that the Commission determines the intervals of conducting appraisals in the educational institutions. The appraisal instrument shall be jointly discussed, completed and signed by the appraiser and appraise. An appraiser, may, where an appraiser does not perform to the expected standards, recommend an appropriate corrective action.Every report shall be submitted to the TSC commission's headquarters at the end of the appraisal period. The TSC further states that notwithstanding the above provisions, she may from time to time issue guidelines on the management of performance appraisal system.TSC (2015) further makes appraisal compulsory by directing a disciplinary action against a teacher who fails to complete and submit an appraisal report to the supervisor, or neglects or refuses to sign and discuss the appraisal report with the supervisor. Furthermore, the commission directs that any teacher who consistently displays poor performance or adverse appraisal ratings may after due process have the services terminated.

There are several studies done on curriculum implementation. For instance, Babafemi (2007) defines education as a combination of life experiences that people obtain to deal with and develop fulfillment from existing in the world.An excellent curriculum should allow individuals to attain optimum individual development and social competence. In relation to the above opinion, quality of a nation's education is related to the level of its prosperity. From the study, a good curriculum should offer adequate opportunity for assessment by experts. Chikemibe and Makamure (2010) carried out a study on effective curriculum assessment in schools in Gambia. According to their study, an excellent curriculum evaluation should have an implementation agent. The teacher plays an important role in curriculum evaluation by transforming the curriculum into schemes of work, syllabus and into lessons that are delivered to students. Adeleke (2006) concurs that stakeholders cannot overemphasize teacher's commitment to curriculum evaluation concerning testing policies in school. Additionally, curriculum evaluation should be well directed from supervision of examinations, setting,ranking and grading, and marking. Subsequently, teachers should consistently follow up on the learners' academic achievements to ensure that there is value added progress. However, Adeleke (2006) only looked at curriculum implementation while this study looked into curriculum evaluation, co-curricular activities, and even students' discipline. Julie (2012) examined effects of teacher evaluations on student achievement and teacher effectiveness. The study observed that data from teacher evaluations should be used to make adjustments with teaching practices and methods. Making adjustments would increase student achievement.The results further showed that employing the new evaluation processes aided our students to be better equipped for a competitive global economy. Teachers who received higher graduation scores observe assessments as a cause for professional confrontation. The teachers also believe 
assessing teacher's weakness and strengths can affect social and personal prestige.

Nolan (2010) studied The Effect of Teacher Ratings on Teacher Performance and the results reported that low-rated teachers saw increases in their students' English and Math test scores. With release of the ratings, high-rated teachers saw little to no change in their student tests. From the release of teacher ratings, these differential responses from low to high rated teachers suggest possible test score gains. School ratings had no extra impact on student test scores. The study discovered that there was no proof that ratings publication affected teacher turnover or classroom composition. Taylor and Tyler (2012)discovered that performance measures and a quality classroom-observation-based evaluation measures could improve mid-career teacher performance both during the period of assessment, consistent with the traditional predictions; and in subsequent years, consistent with human capital investment. However, the estimated improvements during evaluation were less precise. Hadi (2006) studied the Relationship between Teachers' Performance Ratings and the Achievement of their Students Education Organization of Zanjan. Teachers' performance appraisal ratings are related to the achievement scores of their students. Performance appraisal scores were negatively correlated with student achievement. This indicates that there is no relationship between the supervisor performance ratings of teachers and the success of the teachers' students.Ojokuku (2015) studied the influence of performance appraisal (PA), which is a vital HR practice, on the performance and motivation of academics in Nigerian universities. The study acquired samples from four public universities in Southwestern Nigeria. Additionally, the study sourced data with the assistance of a questionnaire, while data analysis used multiple and percentage regression analysis. Findings depicted that the performance appraisal system exert a strong influence on overall performance and academics motivation.

Randy (2005) explored changes in individuals' confidence for job performance as a function of performance evaluation methods. Participants were college students taking coursework leading toward education-related employment. Results showed increases in participants' teacher efficacy in the low-efficacy group, but not in the high-efficacy group. Participants with low teacher efficacy showed improvements in efficacy following review of guidelines for either evaluation method.Kamiti (2014)suggested that Performance Appraisal System acts as an important factor contributing to the motivation of employees. The more transparent and objective the performance appraisal system is in the public service, the higher would be the motivation of employees. The study assessed the effects of Performance Appraisal System on employee motivation in the Department of Tourism while the present study explored the influence of teacher performance appraisal on teacher performance in public secondary schools. Wanjohi (2013) examined curriculum evaluation in Kenya. In the research paper, he identifies with the teacher as key in curriculum evaluation in Kenya. He observes that formative assessment if well implemented by teachers may assist in improving the learning programs in schools. The researcher indicates that the focus of the teachers should be in both formative and summative evaluation. This is due to the fact that during development of a service or a product, or in the case of personal assistance in developing potential and evaluation the level to which required criteria for tenure, promotion and the like are like are met both summative and formative evaluations needed.

Education experts in Kenya have long argued for a formative rather than a summative evaluation of the curriculum, where the former faked a comprehensive view as incorporated various elements and is progressive, instead of the latter that only considers what a candidate does in three weeks (2014, Saturday Nation, September 27,). Challenges abound, though over the formative mode of evaluation but it is an option worth considering. The Saturday Nation, (2014 September, 27 ${ }^{\text {th }}$ ) observes that the bottom line is that the administration of the national examinations should be reviewed, it is presumed that TPA could play a role in ensuring effectiveness in the administration of examinations. Kerry (2013) confirmed that there is evidence that teacher performance is the single most important school variable influencing student achievement. OECD (2009) further confirms that raising teaching performance was most likely to lead to substantial gains in student learning and academic achievement. Stronge (2012) also asserts that student academic achievement varies depending on which teacher the student is assigned to. It is important to note that the policy envisioned that with up-to-date syllabus coverage coupled with effective curriculum evaluation and well-managed student discipline performance in national examinations would subsequently improve. 
Thus, the present study investigated the influence of Teachers Performance Appraisal (TPA) policy on effectiveness in curriculum evaluation in public secondary schools in Kenya.

\section{Research Methodology}

\subsection{Research Design}

A correlational research design was adopted. This is a particular type of non-experimental design used to describe the relationship among or between variables. This design offers empirical evidence signifying two or more variables are or are not interrelated. This evidence contribute to a deeper understanding and relationship of the variables under study. However, the evidence does not create casual relationships. Without such information, there is little sense in examining the relationship in an experimental design context.

\subsection{Study Population}

The study population comprised 334 Principals and 334Deputy Principals of public secondary schools in Kisii County (Kisii County Education Office, 2015). The sample sizes included 179 principals and 179 Deputy Principals and were both obtained through Stratified random sampling technique.

\subsection{Research Instruments}

Questionnaires were used to collect data. Cohen and Marion (2008) also positively identified surveys as cost-effective and easy to administer to a large number of respondents and can be analyzed more scientifically and objectively than other forms. They further indicate that questionnaires can be carried out by the researcher or by any number of people with limited effect on its validity and reliability. Gay (2005) as cited in Aloo (2009) also explains that survey data are usually collected using questionnaires. In this study, the validity of the instruments was calculated by using the Content Validity Index formulae. Instruments were determined to be valid by considering whether they gave information on Teacher Appraisal policy. To ensure the reliability of instruments, a pilot study was conducted. Yaseen (2015) notes that a pilot study is a small scale preliminary study carried out to evaluate feasibility in an effort to improve upon the study design before the performance of a full-scale one. The pilot study involved county Staffing Officer, 18 Principals, and 18 Deputy Principals 15 teachers from the County who were consequently not used in the study.

\subsection{Data collection\& Analysis}

The researcher obtained Ethics clearance from National Council of Science and Technology (NACOSTI) and County Director of Education and TSC-County Director through Director Board of Postgraduate Studies Jaramogi Oginga Odinga University of Science and Technology. The researcher made three trips to the respective schools, first visit school was an introduction, and familiarization to explain what the study was about, and the second was to distribute questionnaires. It took about 30 minutes to fill in the questionnaires after which the researcher collected them himself.

The research analyzed quantitative data using descriptive statistics such as percentages and frequencies, inferential statistics for instance such as Pearson correlation. Besides, the research also used linear regression for analysis.

\section{Results and Discussion}

The study investigated the influence of teacher performance appraisal on effectiveness in curriculum evaluation. This objective was investigated by use inferential statistics, where the null hypothesis was tested.

$\mathrm{H}_{0}$ 2: There is no statistically significant influence of teacher performance appraisal on effectiveness in curriculum evaluation. 
In testing whether the impact of implementation of teacher performance appraisal policy on curriculum evaluation was statistically significant or not, a bivariate Pearson's Product-Moment Coefficient of correlation was calculated. The SPSS results output shown in Table 1.0 indicates that there was indeed a significant relationship between the variables.

Table 1.0: Correlation between Implementation of TPA policy and Effective Curriculum Evaluation

\begin{tabular}{llc}
\hline & & Curriculum Evaluation \\
\hline \multirow{3}{*}{ TPA policy } & Pearson Correlation & .726 \\
& Sig. (2-tailed) & .000 \\
& $\mathrm{~N}$ & 318 \\
\hline
\end{tabular}

*. Correlation is significant at the 0.05 level (2-tailed).

The results in Table 1.0 show a strong and positive significant influence of implementation of teacher performance appraisal policy on curriculum evaluation in public secondary schools. The relationship was significant as signified by the calculated $p$-value of .000 which was less than the $p$ value of .05 . Therefore, the null hypothesis which stated that "there is no statistically significant influence of teacher performance appraisal on curriculum evaluation by teachers in public schools," was rejected. Consequently, the alternate hypothesis was accepted. Hence, it was concluded that an increase in implementation of TPA results in improvement in curriculum evaluation by teachers. This means that for better curriculum evaluation in schools to be achieved, there must be an efficient implementation of TPA policy as recommended by TSC. This finding agrees with Chikemibe and Makamure (2010) who believed that curriculum evaluation should consider implementation agent. The teacher plays a pivotal role in curriculum evaluation by translating the curriculum into the syllabus, schemes of work and lessons to be delivered to the students. Adeleke (2006) also concurs that a teacher's commitment to curriculum evaluation particularly concerning testing policies in school cannot be overemphasized. Curriculum evaluation should be well guided from setting, supervision of examinations, marking, ranking and grading and consistently following up on the learners' academic achievements to ensure that there is value added progress.

To further illustrate this relationship between teacher performance appraisal and curriculum evaluation by teachers a scatter plot was generated as shown in Figure 1.0.

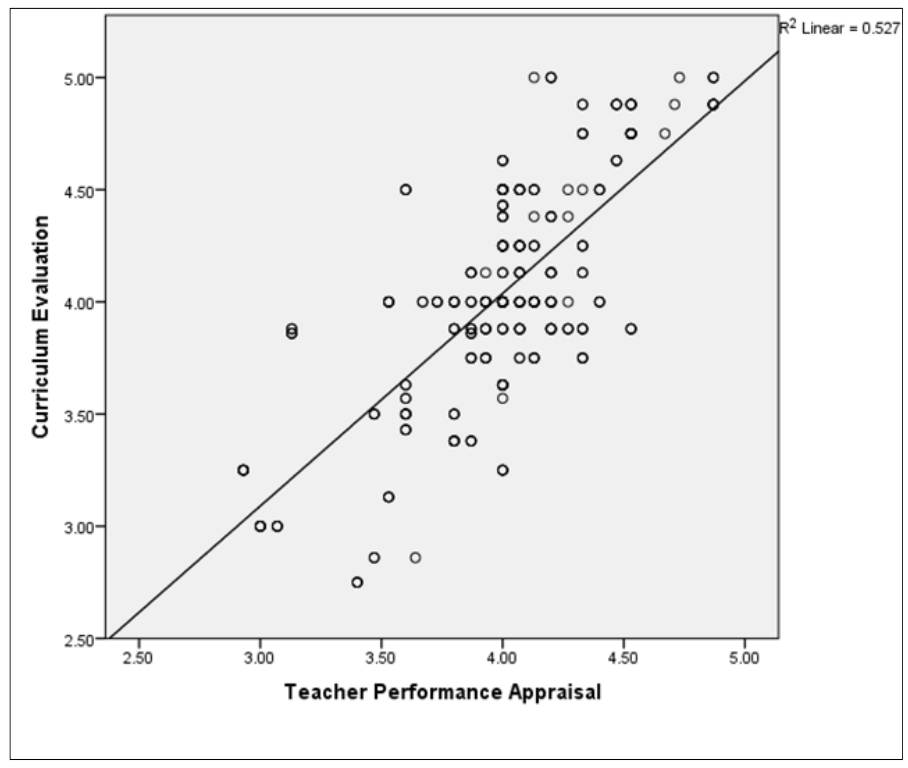

Figure 1.0: Scatterplot graph: Curriculum Evaluation and Teacher Performance Appraisal 
It was demonstrated by the scatter plot that there was a relatively moderate positive correlation between curriculum evaluation and teacher performance appraisal; the pattern of dots slopes to the upper right, implying a positive relationship between the variables. A line of best fit further indicates that there was a positive correlation between the variables; the coordinate points cluster near the line of best fit forming almost a visible pattern; implying that the two data sets were agreeing. The scatters lean to concentrate in the vicinity of the identity line, meaning the relationship was real and not by chance. This finding agrees with Julie (2012) who observed that data from teacher evaluations should be used to make adjustments with teaching methods and practices to increase student achievement. The results further revealed that using the new evaluation processes helped our students be better prepared for a very competitive global economy.

To estimate the level of influence of teacher performance appraisal policy on the effectiveness of curriculum evaluation, a coefficient of determination $\left(R^{2}\right)$ was computed. This was done using regression analysis, and the results were as shown in Table 1.1

Table 1.1: Model Summary on Regression Analysis of Influence of TPA on Level of Curriculum Evaluation

\begin{tabular}{ccccccccc}
\hline Model & $\mathbf{R}$ & $\mathbf{R}$ Square & $\begin{array}{c}\text { Adjusted } \mathbf{R} \\
\text { Square }\end{array}$ & $\begin{array}{c}\text { Std. Error of the } \\
\text { Estimate }\end{array}$ & \multicolumn{4}{c}{ Change Statistics } \\
\cline { 6 - 9 } & & & R Square & $\begin{array}{c}\mathbf{F} \\
\text { Change }\end{array}$ & Change & df1 df2 & $\begin{array}{c}\text { Sig. F } \\
\text { Change }\end{array}$ \\
\hline 1 & $.726^{\mathrm{a}}$ & .527 & .525 & .33563 & .527 & 351.923 & 1316 & .000 \\
\hline
\end{tabular}

a. Predictors: (Constant), Teacher Performance Appraisal

The model shows that implementation of Teachers Performance Appraisal accounted for $52.5 \%$ of the variation in the effectiveness of curriculum evaluation in secondary schools, as suggested by the coefficient of determination $\left(R^{2}\right.$ adjusted $\left.=.525\right)$. This amount of $R^{2}$ indicates that there was a substantial variance shared between the two variables. This means that there was reasonably significant effect by one independent variable on the dependent variable. This finding concurs with Nolan (2010) who reported that low-rated teachers saw increases in their students' math and English test scores. High-rated teachers saw little to no change in their students' tests with the release of the ratings. These differential responses from low- and high-rated teachers suggest possible test score gains from the release of teacher ratings. School ratings had no additional impact on student test scores. Similarly, Kamiti (2014) suggested that Performance Appraisal System acts as an important factor contributing to the motivation of employees. The more transparent and objective the performance appraisal system is in the public service, the higher would be the motivation of employees.

However, to determine whether Teacher Performance Appraisal was a significant predictor of effectiveness in curriculum evaluation by teachers in secondary schools or not, Analysis of Variance (ANOVA) was worked out as shown in Table 1.2.

Table 1.2: ANOVA -Influence of TPA on Curriculum Evaluation

\begin{tabular}{lccccc}
\hline Model & Sum of Squares & Df & Mean Square & F & Sig. \\
\hline Regression & 39.644 & 1 & 39.644 & 351.923 & $.000^{b}$ \\
1 Residual & 35.597 & 316 & .113 & & \\
Total & 75.241 & 317 & & & \\
\hline
\end{tabular}

a. Dependent Variable: Curriculum Evaluation

b. Predictors: (Constant), Teacher Performance Appraisal

The findings of the study established that Teacher Performance Appraisal was a significant predictor of effectiveness of curriculum evaluation by teachers $\left[F(1,316)=351.92, p<.05, R^{2}=\right.$ $.527, \mathrm{R}^{2}$ Adjusted $\left.=.525\right]$. This indicates that effective implementation TPA has significant positive influence on curriculum evaluation. This, therefore means that implementation of TPA can be relied on as a predictor of the effectiveness of curriculum evaluation in secondary schools. The findings are further confirmed by Julie (2012) who argued that teacher appraisal influenced students' 
achievements in examinations. Ojokuku (2015) also showed that the performance appraisal system was also found to exert a substantial impact on the academics' motivation and overall performance.

To determine the actual contribution of implementation of TPA on curriculum evaluation, a linear regression was done to find the magnitude of influence TPA on effectiveness in curriculum evaluation, as shown in Table 1.3.

Table 1.3: Coefficients of Linear Regression: TPA and Curriculum Evaluation

\begin{tabular}{lccccccc}
\hline Model & \multicolumn{2}{c}{$\begin{array}{c}\text { Unstandardized } \\
\text { Coefficients }\end{array}$} & $\begin{array}{c}\text { Standardized } \\
\text { Coefficients }\end{array}$ & T & \multicolumn{2}{c}{$\begin{array}{c}\text { S5.0\% Config.ence } \\
\text { Interval for B } \\
\text { Lower }\end{array}$} \\
& B & Std. Error & Beta & & & $\begin{array}{c}\text { Upper } \\
\text { Bound }\end{array}$ & Bound \\
\hline 1 (Constant) & .248 & .203 & & 1.222 .223 & -.151 & .647 \\
Teacher Performance Appraisal & .947 & .051 & .726 & 18.760 .000 & .848 & 1.047 \\
\hline
\end{tabular}

a. Dependent Variable: Curriculum Evaluation

Regression $Y=a+b x+\varepsilon$

From Table 1.3, it was indicated that if the implementation of Teacher Performance Appraisal were increased by one standard deviation, then the perceived scores in the level of effectiveness in curriculum evaluation would increase by .726 standard deviation units. On the same note, a regression equation was developed to help in estimating the level of curriculum evaluation given the level of TPA. A regression equation, $Y=a+b x+\varepsilon$, was used. In the equation, $Y$ represents Curriculum Evaluation, and $X$ represents the level of implementation of TPA policy. Hence, the optimum level of curriculum evaluation in secondary schools is equal to .248 units $+.947 x$ units. The model is $52.5 \%$ explained by the independent variable, meaning that only $47.5 \%$ was explained by the other factors not covered in this regression model. These findings further confirmed those of Hadi (2006) who believed that teachers' TPA ratings are related to the achievement score of their students. He further argued that a teacher whose appraisal scale is further embedded on his /her duties of actually evaluating what has been taught by him or her would be more focused on the learner. However, this disagrees with Nolan (2010) who indicated that teachers' appraisal had no additional impact on student test scores. Similarly, Taylor and Tyler (2012) found out that a quality classroom-observation-based evaluation and performance measures can improve mid-career teacher performance both during the period of assessment, consistent with the traditional predictions; and in subsequent years, consistent with human capital investment. However, the estimated improvements during evaluation were less precise. Hadi (2006) reported that performance appraisal scores were negatively correlated with student achievement. This indicates that there is no relationship between the supervisor performance ratings of teachers and the success of the teachers' students.

\section{Concluding Remarks}

Concerning contributions of TPA on effectiveness in curriculum evaluation by teachers, the study concluded that teachers had become more committed and focused on offering and invigilating tests to students on a regular basis. However, in a few schools, monetary rewards still played a crucial role as far as marking of such examinations within stipulated time is concerned. It was unanimous that more examinations were being done to gauge mastery of content than before. It was also observed that cases of examination irregularities in national exams had since declined in public secondary schools within the county since the introduction of TPA. The study recommended that The Ministry of Education should offer the regular capacity building to teachers on ways of eliminating examination irregularities. Continuous assessment tests should be strengthened at the school level to reduce the emphasis on national examinations. 


\section{References}

Adeleke, M. (2006). An Appraisal of Curriculum Implementation in Nigeria. Lagos: Macus Publication.

Aloo, J. (2009). Impact of the school Based Teacher Recruitment Policy on the Distribution and Retention of Teachers in public secondary schools in Nyando District Kenya. Unpublished thesis. Maseno University.

Babafemi, T. (2007). An assessment of the implementation of 6-3-3-4 system of Education in Nigeria: Kwara state Institute: Nigeria.

Castler, A.O. (2010). Management Support Qualification and Gender onTeachers Performance at an In-service Course. Nigeria Journal of School Leadership 15(1):12-17.

Chikumbe, T.\&Makamure, R. (2000).Curriculum Theory. Available online fromhttp/www.col.int/stamp/module 13.pdf.

Clark, A.O. (2006). Management Support and Teachers Behaviour. New York: Sorrence publishers.

Cohen, L. Manion, L. \& Morrison, K. (2007). Research Methods in Education. London. Routledge Tailor \& Francis group.

Ekwuene, L. (2005). Education Research Network for West and Central Africa, Ernwaca, Lagos.

Hadi A. (2006). The Relationship between Teachers' Performance Ratings and the Achievement of their Students Education Organization of Zanjan. Applied H.R.M. Research, Volume 11, (1): 75-78.

Julie, A. N. (2012). Effects of Teacher Evaluations on Teacher Effectiveness and Student Achievement. A Published M.ED Thesis, Northern Michigan University.

Kamiti, R.K. (2014). The Effects of Performance Appraisal System on Civil Servants Motivation: A Case Study of the Directorate of Tourism 2006-2014. A Published Research Project, University of Nairobi.

Nolan (2010) .The Effect of Teacher Ratings on Teacher Performance. Retrieved from Http://Home.Uchicago.Edu/ Npope/La_Ny_Paper.Pdf

Ojokuku, R.M. (2013). Effect of Performance Appraisal System on Motivation and Performance of Academics in Nigerian Public Universities. Australian Journal of Business and Management Research, Vol.3 No.03, 2028.

Randy L (2005). Effects of Different Types of Performance Appraisal Information on Self -Efficacy and Job Preference" (1995). Retrieved on $24^{\text {th }}$ March 2017 from. Http://Digitalcommons.Unl.Edu/Dissertations/AAI9611050

Stronge, H.J. (2012). Teacher Evaluation and school improvement: Improving Education landscape. Newbury Park, CA: Sage Publications.

Stronge, J. (2002). Qualities of effective teachers. Alexandria, VA: Association for supervision and curriculum Development.

Wanjohi, M. (2013).Curriculum Evaluation - Kenya Proponents Organization. KENPRO, Nairobi.

Yaseen, A. (2015). Performance Management Practices and Its Impact on Banks' Performance in Pakistan. International Journal of Human Resource Studies, Vol. 5, No. 4: 110-128. 